\title{
Coopetition and Institutional Logics in Tourism
}

\author{
Shuyang Wang*, Veronica Hoi in Fong \\ School of Business \\ Macau University of Science and Technology \\ Macau, China \\ sywang@must.edu.mo*, hifong@must.edu.mo
}

\author{
Jacky Fok Loi Hong \\ Faculty of Business Administration, \\ University of Macau \\ Macau, China \\ fbaflh@umac.mo
}

\begin{abstract}
This study advances the understandings of institutional transition in the tourism literature by integrating two areas of study: the theory and practices of analysis informed by the research on institutional logics and on coopetition. Adopting a qualitative study of four tourism operators and their related organizations in a tourism market, we develop a concept of institutional co-creation to describe how networking, exchanging and framing influence organizational performance. The findings show that in responding to the changes of institutional factors, organizational members in the tourism industry transform their institutional logics through the interaction of coopetition. The present case contributes to the nascent literature on tourism by conceiving the institutional environment for organizational sustainability under a fastchanging tourism economy.
\end{abstract}

Keywords-Co-creation; Institutional logic; Coopetition; Tourism economy

\section{INTRODUCTION}

Coopetition has been used to explain the relationships among different organizations in previous tourism studies. Primarily, these studies only emphasized the outcomes rather than the processes. In fact, the process of "how to coopete" has not yet been properly explored [1]. In essence, only cursory attention has been paid to institutional context, especially the existence of the opposing yet complementary logic. Thus, these unique aspects of coopetition in the fast growing tourism economic environment have led to consideration of this research question - How do institutional logics integrate with coopetitve dynamics to affect the performance of the tourism organization throughout a tourism transitional economy?

By integrating the dual perspective of institutional logics and coopetition, the objective of the article is to explore how tourism organizations are able to maintain survival throughout an transitional economy in the tourism industry. Overall, it attempts to contribute to the tourism literature in three aspects. Institutional logics provide the theory to understand how actors in inter-organizations change their practices and behavior during a transitional economy. Coopetition reveals the underlying patterns of cooperation and competition and their transformation of both. The combination of the dual perspective complements the each component to influence organizational performance throughout a period of institutional change. Following a brief review, the research background is presented in the next section, and then the qualitative approach of using embedded cases is described in the methodology part.
Third, the findings are unfolded in the analysis and the conclusion is summarized at last

\section{THEORETICAL DEVELOPMENT}

\section{A. Institutional Logics}

Institutional logics are shared cognitions among individual and societal levels. They shape rules, guidelines and principles in the organization by applying reasoned judgments and rationalities to reveal a share pattern of values, beliefs, and behaviors among actors [2]. In studying organizational survival and performance in the context of a fast changing tourism environment, some scholars argue that an organization's success depends on the changing relations of competition and cooperation between firms in a competitive environment, in which new institutional logics, such as norms and values are created [3]. However, these studies do not provide a broader understanding of how conflicting-yet-complementary logics are developed or transformed through a dynamic interaction between institutions and organizations. The institutional context which comprehends both formal and informal enablers and constraints in a competitive and cooperative century strongly affects the way tourism actors' logics operate on the industry level. Thus a core idea of how the coopetition perspective complements the study of institutional logics in a changing institutional environment should be explained.

\section{B. Coopetition}

Coopetition in tourism has become a new important phenomenon and has aroused academic attention to explore a pattern of development in which different typologies of discrete relationship, degree of intensity, and influence have been examined [4]. In lieu of separating them in two extreme cases, cooperation [5] and competition [6], research on tourism destinations provides some evidence for understating the positive impacts when organizations engage in coopetition. The contribution of this theme highlights the value creation generated from the interconnectedness of tourism actors, including the competitors, suppliers, customers and complementors in supply chains and networks, which enable organizations to enlarge the "business pie" and simultaneously share the risk and lower the cost of production among them [7]. In particular, the tourism destination makes visible the dual effect of cooperation and competition when customers experience different products and services provided by both private and public allied and competing organizations, which at the same time connect to the destination as a whole [8]. 


\section{METHODOLOGY}

A qualitative embedded case study was adopted in between 2002-2015. We conducted 188 interviews at four tour operators in Macau. The choice of tourism industry as the focus of this study was considered to be suitable since changes occurred in the broader environment in Macau over the past two decades that led to institutional changes, forcing the incumbent firms to shift their institutional logics from independence to interdependence. Consequently, the changes of institutional environment enabled the development of new logics in coopetition. The four operators have been renamed as company $\mathrm{A}, \mathrm{B}, \mathrm{C}$ and $\mathrm{D}$ respectively for the purpose of anonymity and confidentiality of participants. The interviewees cover CEO, general managers, technical directors, consultants, government officers and employees from different business units at the four operators. Interviews were all tape recorded and transcribed within two days. All qualitative data was imported into NVivo 8 and the inteviews were analyzed by the three researchers separately for internal validity. Finally, six first-order categories and three second-order themes emerged after condensing and aggregating the initial codes. Fig. 1 presents the model of first and second order themes.

\section{FINDINGS}

Before the announcement of the tourism industry as a primary industry in 2002 , individual tourist operators compete by taking independent action for their own business performance. They had to realize both advantages and disadvantages in substantial transaction and control cost, and limited power and control mechanisms for monitoring and affecting the behavior of industry operators. However, the evolution of Macau tourism has shifted the orientating behavior and practices into new tourism logic. The new logic of institutional co-creation which incorporates three distinctive functions networking, exchanging and framing - were adopted by the operators. Here, the case of institutional logics that influence the way how tourists actors cooperate and compete have been identified.

\section{A. Networking}

Networking is coded by two distinct but not exclusive categories: exploiting formal partners and exploiting informal institutional partners. Building networks with formal and informal partners helps leverage existing network resources and capabilities of an operator because it facilitates the firm's ability to access and open new networks that have not yet been developed. This process enables actors within the network to access, share, and change their resources, giving rise to competitive dynamics in their institutional environment. Conceptually, formal partners interact with those (people, firms and organizations) who enact different business activities with all actors in the firm, in an environment where all business activities are formally constrained by law and regulations. These partners may not involve any interpersonal activities or arrangements with the employees or actors of the firms directly. Informal partners interact with those (people, firms and organizations) who engage with the people in the firms, in an environment in which they may build up social networks, such as personal relationships, with business professionals and government officials, as well as with friends and relatives in the business environment, where business activities are not constrained by law and regulations. Business relationships of this type are embodied in the interpersonal ties cultivated by the employees or managers in the firms and play an important role in facilitating economic exchange

\section{B. Exchanging}

Exchanging is one of the major components in improving organizational performance and increasing competitive advantage. It involves an act of "sharing in" and "sharing out", showing a degree of intimacy and a direction of reciprocal exchange in the marketplace. It facilitates a better understanding of how resources should be integrated into existing routines. By combining current and new resource bases, tourism firms are likely to improve their performance because exchanging enables a better coping mechanism that firms can deploy to create improved alignment with their coopetitors and adapt more to their industry subsystem activity. The mechanism of exchanging allows firms to accumulate experience; and to articulate and codify knowledge. It is a process that ensures tourism information and customers access to the organization in innovative ways, allowing firms to engage more customers and new possibilities through both organizational and market innovations, which include attributes such as searching, variation, risk-taking, experimentation, playing, flexibility, discovery, new productivity and service. The capacity of firms to sustain themselves in the tourism market is gauged by their ability to learn systematically the effects produced by tourists' values, lifestyles, ideologies, purchasing decisions, and behaviors and the knowledge are shared and diffused among the supply chain operations within the tourism industry. It helps innovation and develops new knowledge capability, thus having a positive effect on such outcomes as the development of new tourism products and services, and possibly leading to economic profitability. Hence, exchanging can be considered a vital capability for continuous survival in competitive industries.

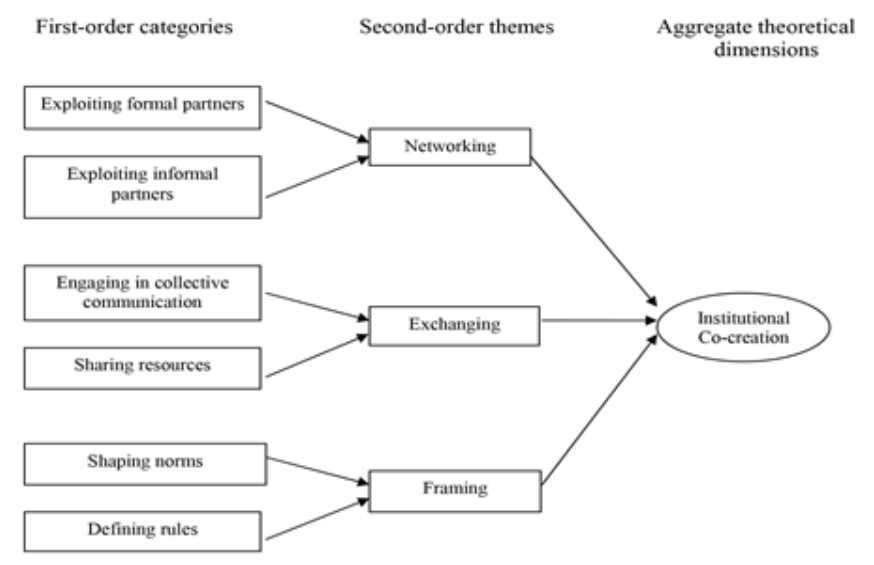

Fig. 1. Theoretical categories of Institutional Co-creation.

\section{Framing}

Framing is defined as a strategic renewal, involving a shift in the cognition of an organization that has the potential to 
exert a substantial effect on its long-term prospects through mobilizing others to accept and support the new rules, norms and beliefs, by setting up a regulatory system and identifying values to change people's underlying mindsets. The provision of a new corporate vision can be used by organizational members to infer norms and rules to guide their daily actions. The courses of action should not only be seen as desirable, but these divergent change implementations should gain the consensus and support of other organizational participants. Internal validation is necessary to reinforce organizational practices and to mobilize organizational members so that they coalesce around a common vision.

Framing an organization's cognition relies on organizational members to: 1) compile rules, and 2) shape norms. The first category is defined here as the conscious obedience to incorporation of the formal regulations that an organization has to conform with the environmental pressures because the approbation of external constituents increases its sustainability or remains the logic of confidence to pursue organizational activities even in institutional transition. It helps people to decide on the championship and resist instability, so continuing to improve their abilities and knowledge in order to increase the firm's competitiveness. Compiling the rules and regulations set up by the government helps reduce organizational vulnerability to adversarial or hostile effect on its goods, services or business conducts and behaviors. The second category helps the organizational members of the firm to fashion a new mindset and articulate a new value for the process of coopetition. This aims to mobilize people to achieve their best performance and enables them to understand the importance of changes in the organization, namely that these will lead to a better outcome for both the individual and the firm. The effect of these strategic renewals reframes a firm's cognition in terms of responding to institutional change. This has been shown to result in the recognition of a new businessto-business approach and the repositioning of firms toward traditional products and services in the tourism system associated with the emerging regime, making them better positioned to take advantage of them. This also benefits firms in that they create relevant complementary assets that facilitate capitalizing on new supply in the industry.

\section{CONCLUSIONS}

By conducting a case study, this study examines how interfirms in the tourism industry develop their own logics in order to compete and cooperate spontaneously throughout the process of institutional change. We have advanced a new institutional co-creation concept that offers an integrated explanation for the pervasive logic of survival, shaping coopetition's structure. The embedded case, in the context of Macau, of the four tourism operators in this study illustrates how three institutional practices or behaviors were developed to evolve with the new and changing coopetitive tourism environment.

The finding explicitly shows that a mere competitive behavior or practice which the operators had employed may not be able to contribute to their stability with respect to accommodating changes in the tourism industry. The structural change in the industry acted as a preeminent driver for a new logic development in tourism, which explained the importance of operators to embrace new practices and behaviors for organizational survival. Previous tourism research on coopetition neglected the path of the institutional context in driving the changing activities or practices of tourism organizations [3] and [4]. In this study, the changes in the character of the organizational activities are linked to the changes in the institutional environment. The institutional logics perspective has been applied to analyze how tourism operators react to the changing economy. The concept of institutional co-creation in this study indicates that coopetition is more a collective process of developing change at the meso level of the tourism industry (i.e., the interorganizational institutions) and points to the role of the individual organizations. The logic of institutional co-creation becomes the idea of "best practice" that governs the daily behaviors and activities of the organizations. The change in developing a conflicting-yet-complementary logic among tourism operators can be seen as both normative and cognitive dimensions of organization. The coherence of change to adopt a new institutional co-creation practice in the operators derives not just from an exogenous need for consistency of the tourism industry, but also from the extent to which this particular competitive and cooperative behavior is shared and embedded among individual tourism actors. Consequently, the norms, value and practices of institutional co-creation between coopetitors are diffused in the tourism sectors which shape individuals' interactions, practices and structures. Through the microfoundation of coopetition, the impact of individual interactions manifest through the role of bridging, sharing and framing in reproducing and transforming the preinstitutionalized competitive logic is shown.

\section{REFERENCES}

[1] K. Czernek and W. Czakon, "Trust-building processes in tourist coopetition: The case of a Polish region," Tourism Management, vol. 52, pp. 380-394, 2016.

[2] P.H. Thornton and W. Ocasio, "Institutional logics," in G. Royston, C. Oliver, S. Roy and S. Kerstin, Eds. The SAGE Handbook of Organizational Institutionalism: Sage Publications Ltd., pp. 99-129, 2008.

[3] Y. Wang and S. Krakover, "Destination marketing: competition, cooperation or coopetition?" International Journal of Contemporary Hospitality Management, vol. 20(2), pp. 126-141, 2008.

[4] V.D. Corte and M. Aria, "Coopetition and sustainable competitive advantage: The case of tourist destinations," Tourism Management, vol. 54, pp. 524-540, 2016.

[5] P. Beritelli and C. Laesser, "Power dimensions and influence reputation in tourist destinations: empirical evidence from a network of actors and stakeholders," Tourism Management, vol. 32, pp. 1299-1309, 2011.

[6] V. Patsouratis, Z. Frangouli, and G. Ananstasopoulos, "Competition in tourism among the Mediterranean countries," Applied Economics, vol.37(16), pp. 1865-1870, 2005.

[7] M. Navelli, B. Schmitz, and T. Spencer, "etworks, clusters and innovation in tourism: a UK experience," Tourism Management, vol. 27(6), pp. 1141-1152, 2006.

[8] Y.v.F. Grängsjö, "Destination networking: Co - opetition in peripheral surroundings," International Journal of Physical Distribution \& Logistics Management, vol. 33(5), pp. 427-448, 2003. 